The Measurement of an

Individual's Organization Map

PAUL S. GOODMAN

Reprinted from ADMINISTRATIVE SCIENCE QUARTERLY Volume 13, No. 2, September 1968 pp. 246-265

Made in United States of America 


\section{The Measurement of an Individual's Organization Map}

This paper proposes a theoretical tramework and operational measure of an individual's organization map, that is his perceptual model of the organization. Data were obtained from two departments in an insurance corporation to study the relationship between the organization map and various structural and personality variables. The analysis gave some support to the validity of the organizationmap scale. The implications of the concept and measure of the organization map for organization theory and administrative practices are discussed.

Paul S. Goodman is assistant professor in the Graduate School of Business at The University of Chicago.

THIS study attempts to operationalize and to identify correlates of an individual's organization map. The concept of an organization map was first presented by Herbert Simon and refers to the individual's perceptual model of an organization. ${ }^{1}$

The major focus of this study is to develop a measure for an individual's organization map that will meet some preliminary tests of internal consistency and validity. Internal consistency of the map regions will be assessed by the Guttman scale, with specific attention to the unidimensionality of the regions and theix interrelationship. Validity of the scale is examined by relating the scale to some structural-demographic and personality variables.

¿ Hexbert Simon, Comments on the Theory of Organizations, American Political Science Revnew, 46 (1952), 1130-1139.
The purpose of developing a measure for an individual's organization map is to provide a tool that can be used to analyze problems in organization theory. For example, in comparative organization analysis, the map measure would provide an empirical method to compare modal perceptual representations of organization reality across different organizations.

\section{THEORETICAL BACKGROUND}

The organization map concept can be understood as a logical outgrowth of Simon's theorizing about the nature of the individual and organization systems. ${ }^{2}$ Unable to cope with the large number of complex organizational cues, the individual has to reduce the stimuli so that he can deal with them. The result is a simplified model of the organization. In this analysis, this concept is developed further both theoretically and empirically. ${ }^{3}$

Field theory is also applicable to the concept of organization map. ${ }^{4}$ Lewrn's lifespace includes the personality region and the environmental region. The environmental region corresponds to the individual's organization map. ${ }^{5}$

Figure 1 represents an individual's lifespace. The personality region $(P)$ is surrounded by various organization map regions $\left(r_{1}-r_{7}\right)$. The regions are subdivisions within organization space which are important in explaining the individual's behavior at a given time. For example, the individual's perception of the authority and reward structures are considered possible regions in an organization map.

Regions are also described by Lewin in terms of differentiation. Two types of differentiation can be noted. First, there is differentiation of regions (e.g., $r_{1}, r_{2}, \ldots$ ) within organization (environ-

2 James March and Hexbert Simon, Organizations (New York: John Wiley, 1958). 3 Simon's account of the development of the ECA in Birth of an Organization: The Economuc Cooperation Administration, Public Administration Review, 13 (Winter 1953), 227-236, provides some amplification of his concept, but the account is very impressionistic and not specifically concerned with systematically operationaiizing the concept.

${ }^{4}$ For further discussion see Kurt Lewin, Field Theory in Social Science, ed. D. Cartwright (New York: Harper, 1951).

${ }^{5}$ No attempt is made to distinguish between Lewin's concept of the realityurreality level. The interview reports are considered to represent the respondent's perception of reality. 


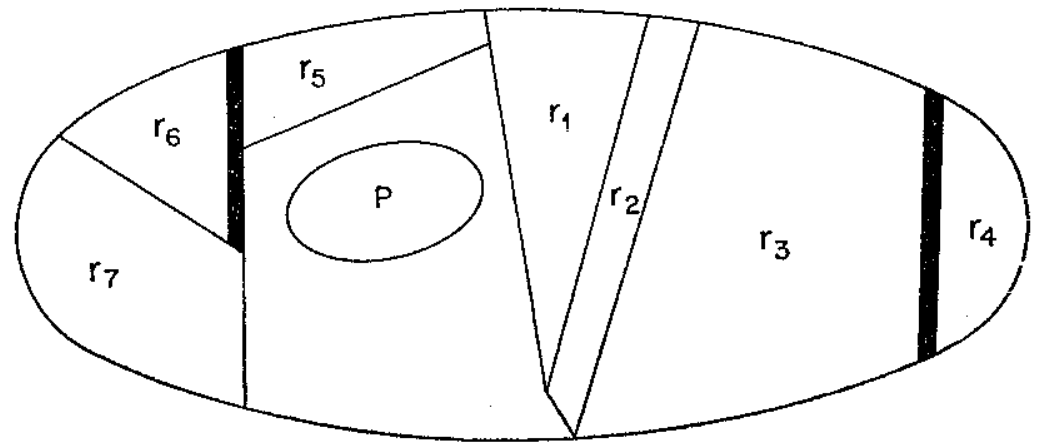

Figure 1. Diagram of Lewin's lifespace.

mental) space. That is, an individual may have only one or many different regions (e.g., his job activity, reward structure, sociometric structure, goal structure, etc.) wathin this map. Second, there is differentiation within regions. For example, an individual's perception of the authority structure (one region) may vary from a limited vertical picture to a complex horizontal and vertical representation. A high differentiator in this analysis is defined as a person who has greater within-region differentiations in more regions than a low differentator.

The relationships among the regions also have theoretical importance for this investigation. Following Lewin we will try to describe regions on both nearness-remoteness and weaknessfirmness continuums. The near-remote continuum refers to the spatial relationship among regxons. In this analysis we are mainly interested in the map (environmental) region's relationship to the personality region in the lifespace. ${ }^{6}$ Region 1 in Figure 1 would be classified as near and region 4 as far. The nearer these regions are to the personality regton, the more central (important) they are to self, and the greater possibility for psychological movement in these regions. The greater the possibility of movement, the more likely that the individual will be aware of differences (subregions) within that region.

${ }^{6}$ At this level of theory development the focus is only on the retationship between the personality region and map regions. Relationship among regions is not discussed, although an important topic.
The weakness-firmness continuum describes region boundaries in terms of their accessibility to the personality region. The firm boundaries shown for regions 4 and 6 indicate they are less accessible. Regrons with firm boundaries are characterized by a higher cost for information than those with weak boundaries. That is, search is more difficult and information less available and, therefore, perceptually these regions are not as differentiated. ${ }^{7}$

\section{VARIABLES}

The organization map is conceptualized in terms of five regions: the individual's perception of the salary structure, promotional structure, financial structure, authority structure, and major organization problems. ${ }^{8}$ These regions were selected because they are complex and thus permit a wide degree of differentiation. Also, the regions can be placed on nearness-remoteness, weaknessfirmness continuums. The reward regions--salary and promotion -because of their immediate impact on the individual are postulated to be nearer to the personality system than the other regions. The financial, authority, and problem regions (i.e., perceived organization problems of the department and corporate levels now and five years from now) probably are more remote and characterized by firmer boundaries in terms of information availability than the reward regions.

From our discussion of the nearness-remoteness, weaknessfirmness continuums we hypothesize that the salary and promotion regions, being nearer to the personality region and characterized by weaker boundaries, would be more differentiated than the other three regions. Figure 2 is a representation of hypothesis 1. Since the major focus in this analysis is relatıng regions to the personality system and not to one another, the regions may vary

${ }^{7}$ A simple $2 \times 2$ classification scheme could be derived from these two contunuums to classify tegions. For example, a region might be near yet inaccessible (firm) That is, a region (e.g., the salary structure) may be important to the individual but inacessible due to the organization's secret pay policy. Or a region could be anaccessible cue to the organizatons sectiot parts accessible such as when an organization publishes extensive organization charts, but if the authoxity region is not mportant (near) to the individual, we would expect this region to be less differentiated.

8 There are clearly other important regions which might have been inciuded such as a sociometric region, power region, information system region, etc.; however, the organization time available prevented their inciusion. 


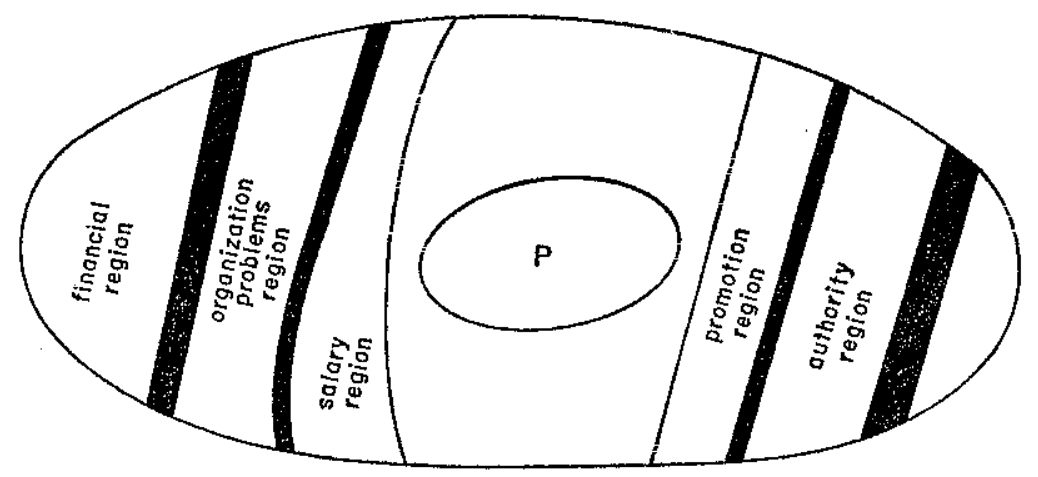

Figure 2. Modal representation of an organization map.

in their relationship to one another but not in their distance from the personality region.

The second hypothesis concerns the unidimensionality of the regions. If the regions can be arranged in terms of the nearnessremoteness, weakness-firmness dimensions, we would expect an individual who differentiates in the more remote (and/or firmer) regions to differentiate within less remote (and/or weaker) regions. Therefore, we hypothesize that the five regions will exhibit unidimensionality as measured by a Guttman scale.

The next hypotheses concern variables which predict to different points along the nearness-remoteness, weakness-firmness continuums and accordingly account for variations in map differentiation. This variation may be explained by structuraldemographic and personality variables. Three structural-demographic variables-length of service, number of jobs held, and hierarchical level-are hypothesized to be positively related to differentiation in an individual's organization map. These three variables are probably related to the type and amount of information received by an individual, which, in turn, are related to greater differentiation. That is, the long service-hugh level in dividual, because of greater access to information, is closer to the weakness end of the weakness-firmness continuum than the low service-low level individual, and therefore exhibits greater region differentration.

On the individual level of analysis, level of aspuration, job in- volvement, and cognitive complexity are hypothesized to be positively related to map differentiation. The individual who aspures to higher positions is apt to learn more about the organization. Job involvement refers to the centrality of work to the individual. ${ }^{9}$ Following the nearness-remoteness continuum, it is argued that the organization regions would be closer to the personality region and thus more differentiated for the individual involved in his job. For cognutive complexity, the degree to which individuals use multiple dimensions in the perception and evaluation of stimuli, ${ }^{10}$ we expect the cognitively complex individual to carry this disposition into the organization, to perceive more regions and to make finer discriminations within regions.

The major hypotheses are summarized as follows:

1. a. The salary and promotion regions will show the greatest map differentiation.

b. The map regions are unidimensional (estimated by the Guttman scale) along the near-remote, weak-firm con. tinuums.

2. Length of service, number of jobs held, and hierarchical level in the organization will be positively related to map differentiation.

3. Level of aspiration, job involvement, and cognitive complexity will be positively related to map differentiation.

\section{Subjects}

\section{METHODOLOGY}

Managerial employees in two claims departments (A and B) of a large insurance corporation were selected as subjects, because the jobs were relatively homogeneous and all worked in the same location. The two departments differed in that they were in separate companies of the larger corporation. This meant they had different authority structures, supervisors, products, and financial structures.

The group in Department $A$ consisted of 33 males-all the em-

${ }^{9}$ Thomas Lodahl and Mathilde Kejner, The Definition and Measurement of Job Involvement, Journal of Applied Psychology, 49 (February 1965), 24-33.

${ }^{10}$ Joseph Vannoy, Generality of Cognitive Complexuty as a Personality Construct, Journat of Personality and Social Psychotogy, 10 (September 1965), 385-396. 
ployees available at the time of the data collection except for one unwilling employee. The average age was 34 (the range was 25 to 55 ), and 94 percent had completed college. The group in De partment $B$ consisted of 25 males and 4 females, all the employees in the Department who were performing activities similar to those performed by the employees in Department A. The average age was approximately 29 (the range was 19 to 45 ), and 86 percent had completed college.

Five months separated the data collection in the two departments. There is no evidence of any communication between these departments.

\section{Measurement Procedure}

The measure was developed in three stages: an interview, rating of interview responses, and analysis of rating scores by a Guttman scale.

The open-end interview, which lasted approximately $75 \mathrm{~mm}$ utes, was designed to tap the respondent's phenomenological view of the organization regions. For example, in the question on the authority region, the respondent was asked to sketch the authority relationships in the organization.

The rating procedure was designed to distinguish between no differentration and some differentuation rather than degrees of differentiation. To determine the rating criteria, a sample of responses for a dimension was examined. Analysis of the distribution of responses provided a basis for criteria to distinguish between no differentration and some differentiation. For example, responses to the authority region question seem to fall into three categories: minimal specification of authority relationships in the department, specification of authority relationships in the department and in the division, and specification of relationships in the department, division, and corporation. An individual specifying only department relationships (which consisted of their supervisor and his supervisor) was given a no-differentiation score. After the scoring scheme was developed, it was applied to the interviews in both departments.

Since the rating categories were derived from a sample of responses in one department, their application in another depart- ment was important to test the extent to which they could be generalized. The average rank order correlation among ratings of the raters was .75 for Department A and .79 for Department $B$. This comparability of agreement between raters in the two departments provided some evidence that the rating categories could be generalized.

Finally the rating categories were translated into a no-differentiation ( 0 ) and some-differentiation (1) score to permit analysis by a Guttman scale. Analysis of the scale provides information about the relationship among regions in terms of differentiation and the degree of individual differentiation across regions. A summary of these stages for each region follows.

1. Authority region. Subjects were asked to sketch the authority relationships (organization chart) of their department, the division of which it was a part, and the company. Names were to be attached to respective job titles whenever possible. Rated for horizontal and vertical extent, an individual received a score of 5 if his sketch included the company, division, and department relationships, 3 for division and department relationships, and 1 for department relationships only; 4 and 2 represented gradations in the rating scheme. In the Guttman scale, a $5-2$ rating was reduced to a differentiated score ( 1 ) and a 1 rating to an undifferentiated score $(0)$.

2. Reward-salary region. Each subject was asked to indicate: (1) salary ranges for different hierarchical levels, (2) critical factors determuning his salary, and (3) the people and procedures involved in determining his salary. Responses for each question were rated on a 3 to $l$ scale, and a total rating for all items was then dernved. The total rating was translated into a score for the Guttman scale. Individuals with a total rating of 3 or 2 received a differentiated score $(\mathrm{I})$; those with a total rating of 1 received an undifferentiated score $(0)$. For example, a high differentiator might have specified at least four salary levels beyond his own; a low differentiator might have stated that he had no knowledge of the salary ranges above his own.

3. Promotion region. Subjects were asked their views on the opportunities for promotion for their bosses, factors determining their own opportunities for promotion, and the pattern of pro- 
motion in the department. Responses were rated in a manner similar to the salary questions and converted into a differentiated (1) or undifferentiated (0) score. One high differentuator, for example, compared the pattern of promotion in his department with that in a competitor's claums department. Low differentiators, on the other hand, generally reported they had "no idea" or were "uncertain" about the department's pattern of promotion.

4. Organization-problem region. Subjects were asked to list problems currently faced by the president, problems to be considered in five years, and problems presently faced by the manager of their own department. Responses were rated and then reduced to a differentiated or undifferentiated score. Those focussing on computer technology, government relations, new marketing programs, and major top-level retirements as major organization problems were considered high differentiators. Department problems generally included specific problems resulting from a recent organization change, difficulties with clients, computerization, and so on. Those who did not respond to the questions on problems of the president and identified department problems in a very general way (that is, to make claim processing more efficient), were considered low differentiators.

5. Financial region. Questions in this region focussed on the respondent's knowledge of the company's sales, market position, and the general financial picture. Responses to these questions were rated on a 3 to 1 scale. The total rating derived was then reduced to a differentiated or undifferentiated score. One high differentiator, for example, specified in detail the company's market standing, often distinguishing between mutual and stock companies, and among the sales of different products sold by his company.

Other variables such as length of service, number of jobs held, and hierarchical level were gathered from the interview or company records.

Level of aspiration was measured by asking individuals how high they expected to go in the organization. This question was distinguished from how high they would like to go. Measures of the other personality variables were gathered from a questionnaire given to the subjects after the initial interview.
Job involvement was measured by a short form of a scale developed by Lodahl and Kejner. ${ }^{11}$ Six Likert-type items, such as "The major satisfaction in my life comes from my job," were used. The theoretical range was from 6 to 36 ; the actual range varied from 13 to 33, with a low score designating high involvement.

Cognitive complexity was measured by the Kelley Role Repertory Test. ${ }^{12}$ Subjects were asked to determine in what way two people were similar and yet different from a third. The people they rated were those associated with the respondent at work. A simple count of the number of different constructs used to differentiate among individuals was the score of cognitive complexity; the highest score was 15 , the lowest 5 .

The second measure of cognitive complexity was an index developed from two semantic differential scales. Respondents were asked to distinguish between the most-preferred and least-preferred co-worker on 17 bipolar-adjective continuums (8-point scale). The complexity index was the difference score for each bipolar adjective between the most-preferred and least-preferred worker summed, tumes the number of different paurs of scale values used on the 17 bipolar-adjective continuums. A pair referred to the two scores used to describe the most-preferred and least-preferred worker on the same bipolar continuum. The greater the number of different pairs used, the more the respondent was differentrating among the 17 bipolar continuums. If an individual gave a score of 8 to the most-preferred worker and 1 to the least-preferred worker on each of three continuums, his score would be $21[(7+7+7)(1)]$; whereas an individual using pairs 8-1, 7-1, 6-1, would receive a score of $54[(7+6+5)(3)]$. This scoring procedure was designed to reflect a more sensitive measure of differentiation than had been previously attained with these scales. ${ }^{13}$ The index distinguished between the individual who perceived the most-preferred and least-preferred worker as

${ }^{11}$ Lodahl and Kejner, op. cit.

${ }^{12}$ George Kelley, The Psychology of Personal Constructs (New York: W. W. Norton, 1955), Vol. I, ch. v.

${ }_{13}$ These two scales were selected for their face validity and extensive predictive validity as indicated in F. Fiedler, "The Contungency Model: A Theory of Leadership Effectiveness," in Basic Studies in Social Psychology, eds. H. Prostansky and B. Seidenberg (New York: Hoit, Rinenart and Winston, 1965), pp. 538-539. 
completely different along all dimensions (i.e., all his parrs were 8-1 pairs), and the individual who saw that along some dimensions, the most-preferred and least-preferred workers were the same, while along other dimensions they were different.

\section{RESULTS}

\section{Scale for Organization $M a p$}

The differentiated ( 1 ) and undifferentiated (0) scores from the total ratings for each region were scaled. ${ }^{14}$ The highest total score was 5 , the lowest 0 . The coefficient of reproducibility of the scale was .87 for Department A; the minimal coefficient of reproducibility was .58 . The marginals for each region stated in terms of percentage of differentiation are: financial 85 , salary 67 , promotion 65 , organization problems 38 , and authority 35 .

The coefficient for the scale in Department B was .92; the minimal coefficient .68. Marginals for the five regions are: promotion 93 , salary 89 , organization problems 72 , authority 51 , and financial 37.15

These results seem to support the unidimensionality of the scale regions. The relationships among the regions are more complex. The salary and promotion regions appear next to each other in both scales, as hypothesized. However, they are the most differentiated only in the Department B scale, while ranked second and third in differentiation in Department $A$.

\section{Structural Relationships}

To analyze the predicted association between map differentiation and hierarchical level, individuals were divided into high differentiators (scale score 5-3) and low differentiators (scale score $2-0)$. Although it would have been better not to collapse the map scale and to examine scale values individually, the small sample size did not permit this type of analysis. There were 8 hierarchical

14. The Goodenough technique was used in developing the scaies; see Allen Edwards, Techniques of Attitude Scale Construction (New York: Appleton-CenturyCrofts, 1957), p. 184.

15 The marginais are fairly well distributed in both scales. The minimal coefficient of reproducibility indicates that the reported coefficients are not a function of extreme marginals.
Table 1. Relationship between hierarchical level and differentiation in Department A.

\begin{tabular}{ccc}
\hline & \multicolumn{3}{c}{ Hierarchical ievel } \\
\cline { 2 - 3 } Map score & Supervisory & Nonsupervisory \\
\hline All scores & 14 & 8 \\
$5-3$ & 3 & 8 \\
$2-1$ & & \\
Extreme scores* & 10 & 1 \\
$5-4$ & 1 & 6 \\
$1-0$ & &
\end{tabular}

levels in Department A, and 7 in Department B. The level breakdown in Table 1 distinguishes between those in supervisory and nonsupervisory (but still managerial) positions.

Although the predicted relationship between map differentiation and hierarchical level is not satistically significant for Department A (Table 1), two observations seem important; (1) that high differentiators were found in low-level and high-level jobs; and (2) that few low differentiators are found in high-level jobs. ${ }^{10}$ Hierarchical level was further analyzed by examining only extreme differentiators; i.e., individuals scoring $5-4$ and $1-0$. The results (Table 1 ), now statistically significant, indicate that low differentiators are found in low-level positions and high differentiators in high-level positions. The results also suggest that the organization-map scale may be more sensitive at the extreme scale values.

The results for Department $B$ were the same. (See summary of data in Table 3.)

The pattern observed for the other two structural variables showed that low differentiators were not long-service employees, nor had they experienced frequent job changes. The high differentiators, on the other hand, were found in both short and long job-service categories and in few and many job-change categories.

${ }^{26}$ Data were analyzed by the chi square test or the Fisher Exact Probability Test, with statastical levels determined from Table I in S. Siegel, Nonparametric Statistics (New York: McGraw-Hill, 1959), pp. 256 ff. 
Since the three variables are positively related to each other, a separate analysis would have been inappropriate; therefore a multiple regression analysis on the combined samples from both departments was performed to determine the influence of the different variables on the organization-map scale. Hierarchical level accounted for more of the variation than the other factors, followed by length of service and number of job changes; the partial correlations are hierarchical level, .42, length of service, .15 and number of job changes, .06 .

Although this analysis suggests that hierarchical level may be a more important predictor of scale scores for the organization map than service or job-change categories, both service and number of job changes can differentially affect the organizational information received by the individual, which in turn may influence the extent of map differentiation. The problem is that in the population studied, long job service was a necessary, though not a sufficient condition for attanning high-level jobs. That is, all high-level employees had long experience and generally more job changes, although not all long-service (and frequent job-change) employees were in high-level jobs. A high-level individual therefore had greater access to organizational information and consequently greater differentiation, not only because of his present position but also because of the length of his job experience and frequent job changes. In an organization where advancement is less dependent on length of service, the relative umportance of service and job-change varuables may be clearer.

\section{Individual Variables}

Since high differentiators appeared in both low and high categories for the hierarchical position, length of service, and number of job changes, it appeared that other variables than these three structural dimensions must be important in understanding differentiation in the organization map.

Level of aspiration. It was hypothesized that individuals who aspired to higher organization positions would learn more about the system they expected to move into than individuals with low aspirations. The scores on level of aspiration were sorted into those individuals not expecting further advancement (low) and those expecting some advancement (high). ${ }^{17}$ Of those having high levels of aspiration, 15 had map scores of 5-3 and 3 had map scores of $2-0$. Of those having low levels of aspiration, 7 had map scores of 5-3 and 8 had map scores of $2-0$. The data seem to support the positive association $(p<.05)$ between level of aspiration and map differentiation. Individuals who aspired to higher organization positions, no matter what their length of service or hierarchical level, seemed to have more differentiated maps..$^{18}$

Similar results were obtained for Department B (Table 3).

Structural variables, level of aspiration, and differentiation of organzation map. To refine the analysis further, the interrelationship among the structural variables, level of aspiration, and differentration of organization map was examined. Controlling for level of aspiration, there appeared to be no relationship between hierarchical level and differentration of organization map for the individuals with a high level of aspuration, and a significant positive relationship $(p<.05)$ for individuals with low level of aspiration. This finding, which appeared in both departments, seemed to indicate that hierarchical level influences differentiation of organization map more in the low-aspiration group. Similarly, controlling for hierarchical level, there was no significant association between level of aspiration and differentiation of or. ganization map for the supervisory group, and a significant association $(p<.05)$ for the nonsupervisory group. These findings, which appeared in both departments, suggest that level of aspiration influences differentiation only in the nonsupervisory group.

Both sets of findings seem to indicate that at a high hierarchical level or at a high level of aspiration, the second variable (either level of aspiration or hierarchical level) is not directly related to organization-map differentration, while at low levels it is. This suggests that at low levels, for example, where information is relatively limited and equally available, individuals motivated to

\footnotetext{
${ }^{17}$ Some andividuats did not respond to the question on level of aspiration, or thear responses could not be rated, therefore, the totals for both departments changed in this analysis

18 There are no statistically significant relationships between level of aspiration and the structural variables. This would suggest that level of aspiration can be
} considered an independent predictor of map differentiation. 
Table 2. Relationship between individual variables and organization map scores in Department B.

\begin{tabular}{|c|c|c|c|c|c|c|c|c|}
\hline \multirow[b]{3}{*}{ Variable } & \multicolumn{8}{|c|}{ Map score } \\
\hline & \multicolumn{2}{|l|}{5} & \multicolumn{2}{|l|}{4} & \multicolumn{2}{|l|}{3} & \multicolumn{2}{|c|}{$2-1$} \\
\hline & Score & $N$ & Score & $N$ & Score & $N$ & Score & $N$ \\
\hline Mean job involvement* & 21.3 & 8 & 22.6 & 5 & 26.8 & 6 & 25.8 & 7 \\
\hline $\begin{array}{l}\text { Mean number of } \\
\text { different constructs } \dagger\end{array}$ & 9.07 & 7 & 8.50 & 4 & 9.35 & 7 & $8.9 \mathrm{l}$ & 6 \\
\hline $\begin{array}{l}\text { Indext of cognitive } \\
\text { complexity }\end{array}$ & 6.20 & 7 & 5.97 & 4 & 6.65 & 4 & 4.40 & 6 \\
\hline
\end{tabular}

* Low values equal high anvolvement; not significant.

$¥$ Index $=$ difference $X$ number of different pairs $/ 100 ; t=2.34, p<.025$.

gather additional information will develop more region differentiation. At higher levels, however, the motivation to gather information yields a smaller amount of additional differentiation, because of the relatively greater amount of information available at such higher levels.

Job involvement. It was hypothesized that the higher the jobinvolvement score, the more central the job was to the individual, and the more likely that he would have a differentiated organization map. Table 2 presents mean job involvement for different map scores. ${ }^{10}$ The general relationships indicate that high differentiators are more involved in their jobs than low differentiators. However, the results are not significant, and the trend is not consistent, with some individuals scoring three on the map-differentiation score, thus showing lower job-involvement scores than individuals scoring two and one. Therefore, further investigation with a larger sample distributed in all categories is needed, before the relationship between map scores and job involvement can be specified.

An assumption underlying the job involvement hypothesis is that the centrality of job to the individual is equivalent to cen-

${ }^{19}$ Data for Job involvement and cognitive complexity were collected only in Department B. Since some respondents did not complete the forms, the sample size varies. trality of the organization for him. It is quite possible that the job might be very important to the individual, but that the organization as measured by the regions in the scale is unimportant. Combining the measure for level of aspiration with that for job involvement makes it possible to identify degrees of centrality of both job and organization for the individual. Map scores for the following groups were: high level of aspiration and high involvement $\bar{x}=4.45(N=7)$, high level of aspiration and low involvement $\bar{x}=4.0(N=4)$, low level of aspiration and high involvement $\bar{x}=3.4(N=5)$, low level of aspiration and low job involvement $\bar{x}=2.5(N=8)$. (For these data $F_{(3,20)}=4.48$ $p<.025$.) Individuals with high levels of aspiration and high job involvement show the greatest differentiation in organization map, while individuals with low level of aspiration and low job involvement show the lowest differentiation in organization map. Level of aspiration seems to be a better predictor, but given the small sample size, no definitive comment is possible.

Cognitive complexity. It was hypothesized that the predisposition to view stimuli complexly would be generalized to the organizational settung, therefore an independent measure of cognitive complexity would be related to differentiation of organization map. The Role Repertory Test, a measure of cognitive complexity, is scored for the number of different concepts the subject uses to find similarities and differences in a set of individuals. The mean number of concepts used for each map score is presented in Table 2 and shows no systematic or statistically significant relationships between differentiation of organization map and cognitive complexity.

In a previous analysis of structural variables, level of aspiration, and organization-map scores, 1t was pointed out that hierarchical level has a differential effect on the personality-map score relationship. That is, in low hierarchical positions, level of aspiration was related to map differentiation. The implication in this finding as that, holding hierarchical level constant, personality dimensions contribute to map differentration. To extend this observation to the cognitive complexity dimension, measured by the Role Repertory Test, the population was divided into individuals with high and low hierarchical positions, and high and low map scores. 
The mean cognutuve complexity score for the low hierarchical level, high map group (10.54) was significantly higher than for the low level, low map group (8.91), where $t=1.96$, and $p<.05$. Since this measure of cognitive complexity was not related to level of aspiration, it appears that cognitive complexity as well as level of aspiration contributes to differentiation in an individual's organization map.

The second measure of cognitive complexity, an index derived from ratings on semantic differential scales for the most-preferred and least-preferred worker, was also related to map differentiation, as shown in Table 2. The high differentuators $(5-3$ scale score) seem to score higher on the cognutive complexity index than the low differentiators, $t=2.63, p<.025$. Controlling on hierarchical level, high differentiators in low-level positions also seem to score higher on the index $(\bar{x}=6.51)$ than low differentiators $(\bar{x}=4.40), t=3.14, p<.005$.

The results for the latter index of cognutive complexity may be clearer because this measure has greater face validity in the industrial setting and it is less frustrating to complete than the Role Repertory Test.

It might be objected that all that this hypothesis states is that people who see the world as complex also see their organizations as complex. Two qualifications are necessary to that observation: first, the relationship between a personality measure and its generalizability to a behavioral sphere is not obvious, and is an important area for empirical confirmation; second, the complexity measures seem to predict better at lower than at higher organization levels.

The relationshup between the three personality dimensions and differentiation in organization map can be summarized as follows: level of aspiration, job involvement, and cognitive complexity (as measured by the semantic differential scales) are related to variations in organuzation map. If the structural variable-hierarchical level-is introduced, there is a stronger relationship between the personality dimensions and organization-map scores for the lowlevel group. Since the three personality dimensions are not significantly related, they can be considered as independent con. tributors to differentiation of organization map for individuals
Table 3. Summary of results.

\begin{tabular}{|c|c|c|c|c|}
\hline $\begin{array}{l}\text { Relationship of } \\
\text { variables to } \\
\text { organuzation map }\end{array}$ & Dept. A & Dept. B & $\begin{array}{l}\text { Relationship of } \\
\text { variables to } \\
\text { organızation map }\end{array}$ & Dept. B \\
\hline Hierarchical level* & $\mathrm{p}<.005$ & $\mathrm{p}<.01$ & Cognitive complexity & NS \\
\hline Level of aspiration & $\mathrm{p}<.05$ & $\mathrm{p}<.05$ & Supervisory & NS \\
\hline Supervisory & NS & NS & Nonsupervisory & $p<.025$ \\
\hline Nonsupervisory & $p<.05$ & $\mathrm{p}<.025$ & Cognitive compiexity & $\mathrm{p}<.025 \$$ \\
\hline Job involvement & & NS & Supervisory & NS \\
\hline Level of asprration & & $\mathrm{p}<.025$ & Nonsupervisory & $\mathrm{p}<.05$ \\
\hline
\end{tabular}

in lower-level positions. Table 3 summarizes the findings for both the structural-demographic and personality variables.

\section{DISGUSSION}

The findings presented seem to support the possibility of operationalizing the concept of the organization map. The relatively high coefficient of reproducibility suggests there is some internally consistent relationship among the regions. The fact that the coefficient in the scale for Department B was high and similar to that for Department A provides some cross-validation on both the rating categorles from which the scale is derived and the reproducibility of the scale.

The predicted relationships for position and degree of differentiation within the regions were generally borne out. The reward regions (salary and promotion), hypothesized to be nearer and characterized by weak boundaries, appeared adjacent in the scale and highly differentiated. The appearance of the financial region as most differentiated in Department $A$ and least differentiated in Department B can be explained by the recent downtrend in Company A's financial situation. 'There is evidence from the interviews to suggest this negative news traveled widely (weak boundaries) and the respondents perceived that the financial reversal would affect their jobs (nearness) in terms of reduced salary, advancement opportunities and increased budgetary con- 
trols. The least differentiated position of this region in Department $B$ follows from the original hypothesis which characterized the company's financial structure as remote and firm (low infor. mation availability) in regards to region boundaries. (There had been no change in Company B's financial picture, which generally was favorable.) Since the questions, rating categories, and interrater reliabilitıes were generally the same for both departments, the differences in the position of the financial region may be attributed to differences between the departments rather than some methodological artifact.

The validity of the scale received some verification in the findings for the individual and structural variables; that is, an individual's organization map seems related to his ability (cognitive complexity) and motivation (level of aspiration), as well as his hierarchical position within the organızation.

Since the present analysis is the first attempt to measure a complex concept, a number of critical issues underlying this analysis should be raised before the significance of the organization map as a theoretical and administrative tool can be assessed. First, the phenomenological basis of the map measure could be criticized. It could be argued that regions are being forced into the individual's organization space, and that the unit of analysis is not the individual. Much time was devoted before actual data collection, however, to open-end interviews in a related industrial population to determine some feasible regions. After the regions were identified, it was considered more useful to move to a semistructured instrument which would permit greater standardization of questions and greater quantification of responses. As to the unit of analysis, although the data have been presented in an aggregated form, the major focus has been on the individual; that is, from each scale score it should be possible to describe an individual's organization map along the selected regions. For example, a scale score 5 suggests a map where all organization regions are directly adjacent (near) to the personality region and exhibit weak boundaries with regard to the personality region.

An associated issue concerns the specification of the nearnessremoteness, weakness-firmness continuums in this analysis. In a strict Lewinian sense this information can be obtained only em- pirically and not a priori. Clearly an improvement would be to develop an independent check on a region's position along these two continuums. However, it should be pointed out that our concern is not with the individual per se, but how the individual operates in a larger social system. To the extent that the organization selects out certain individuals, and structural uniformities (e.g., goals, technology, etc.) exist, there probably will be some basis for inferring region position and uniformities in organization space.

The significance of the map concept and scale rests not only in the operationalization of the concept itself, but in its utility in dealing with substantive organizational questions. After some methodological issues have been resolved, such as the identification and measurement of new regions, the examination of the generalizability of the measurement procedures in different organizations, and the analysis of the relative contribution of structural and individual variables to the organization-map score, two general research approaches can be followed. First, differences in modal organization maps in different types of organizations could be examined. For example, if the modal authority region for normative, coercive, and economic organizations seemed similar, some of the inferences about the differences among these organizations could be questioned. Also, the map measure could be used to investigate the similarities in regions for different types of organizations.

A second approach could be predictung from the scale of differentiation to some behavior in the organization. For example, one might hypothesize that the more differentiated the individual's view of the organization's information system, the more effectively he could perform his job. Or the more differentiated his view of the power region as distinct from the authority region, the more effective he would be in utilizing the information he collected. A related problem would be to extend the present analysis of the determinants of region differentiation. For example, examination of other structural-demographic factors, such as education, skill, degree of professionalization, and others, would contribute to an understanding of the bases of differentiation. 